\title{
Stable isotope-resolved analysis with quantitative dissolution dynamic nuclear polarization
}

Lerche, Mathilde Hauge; Yigit, Demet; Frahm, Anne Birk; Ardenkjær-Larsen, Jan Henrik; Malinowski, Ronja Maja; Jensen, Pernille Rose

Published in:

Analytical Chemistry

Link to article, DOI:

10.1021/acs.analchem.7b02779

Publication date:

2018

Document Version

Peer reviewed version

Link back to DTU Orbit

Citation (APA):

Lerche, M. H., Yigit, D., Frahm, A. B., Ardenkjær-Larsen, J. H., Malinowski, R. M., \& Jensen, P. R. (2018).

Stable isotope-resolved analysis with quantitative dissolution dynamic nuclear polarization. Analytical Chemistry, 90(1), 674-678. https://doi.org/10.1021/acs.analchem.7b02779

\section{General rights}

Copyright and moral rights for the publications made accessible in the public portal are retained by the authors and/or other copyright owners and it is a condition of accessing publications that users recognise and abide by the legal requirements associated with these rights.

- Users may download and print one copy of any publication from the public portal for the purpose of private study or research.

- You may not further distribute the material or use it for any profit-making activity or commercial gain

- You may freely distribute the URL identifying the publication in the public portal 


\section{Technical Note}

Subscriber access provided by DTU Library

\section{Stable isotope-resolved analysis with quantitative dissolution dynamic nuclear polarization}

Mathilde Hauge Lerche, Demet Yigit, Anne Birk Frahm, Jan Henrik

Ardenkjær-Larsen, Ronja Maja Malinowski, and Pernille Rose Jensen

Anal. Chem., Just Accepted Manuscript • DOI: 10.1021/acs.analchem.7b02779 • Publication Date (Web): 04 Dec 2017

Downloaded from http://pubs.acs.org on December 7, 2017

\section{Just Accepted}

"Just Accepted" manuscripts have been peer-reviewed and accepted for publication. They are posted online prior to technical editing, formatting for publication and author proofing. The American Chemical Society provides "Just Accepted" as a free service to the research community to expedite the dissemination of scientific material as soon as possible after acceptance. "Just Accepted" manuscripts appear in full in PDF format accompanied by an HTML abstract. "Just Accepted" manuscripts have been fully peer reviewed, but should not be considered the official version of record. They are accessible to all readers and citable by the Digital Object Identifier (DOI®). "Just Accepted" is an optional service offered to authors. Therefore, the "Just Accepted" Web site may not include all articles that will be published in the journal. After a manuscript is technically edited and formatted, it will be removed from the "Just Accepted" Web site and published as an ASAP article. Note that technical editing may introduce minor changes to the manuscript text and/or graphics which could affect content, and all legal disclaimers and ethical guidelines that apply to the journal pertain. ACS cannot be held responsible for errors or consequences arising from the use of information contained in these "Just Accepted" manuscripts. 


\section{INTRODUCTION}

An increasing quest for systems approaches to biochemical understanding in living organisms makes NMR analysis of metabolism still more attractive. In conjunction with stable isotope labeling, NMR provides the possibility to directly determine metabolite composition of complex mixtures and to perform in situ analysis of pathway dynamics from live cells and whole organisms. ${ }^{1}$ Augmented sensitivity and resolution of the NMR signals can be gained by ex situ signal enhancement e.g. obtained with dissolution Dynamic Nuclear Polarization $(\mathrm{dDNP}){ }^{2}$ The well-established real-time kinetic dDNP NMR experiment offers detection of the direct conversion of a hyperpolarized substrate in a cell suspension with sub-second resolution. $^{3}$ This type of experiment allows the determination of rate constants within a one-minute time window after addition of the substrate to the cell suspension. This transient experiment, however, requires high up-take and turnover rates for its success.

Changing the order of events in the described DNP signal enhanced experiment could eliminate any restriction on time scale. Such an experiment would involve incubation of live cells or whole organisms with stable isotope labeled substrates, extraction of metabolites and quantitative dDNP NMR of the extracts. Such complementary strategy has previously been applied for therapeutic drug monitoring in animals by analyzing systemic and excreted metabolites in blood and urine ${ }^{4}$, for characterization of physical parameters of metabolites ${ }^{5}$ and as metabolomics approach for component analysis of plant and breast cancer cells. ${ }^{6}$ In general, the complementary strategy of dDNP on metabolite extracts, benefit from the high sensitivity and resolution provided by hyperpolarized samples in highfield NMR spectrometers, the quantification by comparison with an internal standard, and the capability to monitor slow metabolic transformations.

Here we are focused on obtaining dynamic labeling patterns using dissolution DNP NMR for quantification of relative pathway activities. We demonstrate a robust protocol for quantitative dissolution DNP (qdDNP) sensitivity enhanced isotope tracer analysis by NMR. Living cancer cells are incubated with uniformly ${ }^{13} \mathrm{C}$-labeled glucose at different time points, metabolites are extracted, hyperpolarized and subsequently analyzed with NMR allowing reconstruction of cancer type specific metabolic pathways.

\section{EXPERIMENTAL SECTION}

Sample preparation to evaluate polarization, solubility and concentration. Stock solutions of five test compounds were made, ${ }^{13} \mathrm{C}_{1}$-pyruvate $(27 \mathrm{mM}),{ }^{13} \mathrm{C}_{1}$-lactate $(34 \mathrm{mM})$, ${ }^{13} \mathrm{C}_{1}$-Alanine $(54 \mathrm{mM}),{ }^{13} \mathrm{C}_{1}$-Acetate $(35 \mathrm{mM})$ and ${ }^{13} \mathrm{C}$ HP001 (50 mM, 1.1-bis (hydroxymethyl) cyclopropane)). A polarization medium was made of $314 \mathrm{mg}$ Milli-Q-water, $70 \mathrm{mg}$ trityl radical OX063, $1227 \mathrm{mg}$ glycerol and $28.8 \mathrm{mg}$ Gadoteridol $(100 \mu \mathrm{mol} / \mathrm{g}) .5 \mu \mathrm{L}$ of each stock solutions 
were mixed with $100 \mu \mathrm{L}$ polarization medium, $25 \mu \mathrm{L}$ Milli-Q-water, and $11.58 \mathrm{mg}\left[\mathrm{U}-{ }^{13} \mathrm{C}, \mathrm{D}\right]$ glucose $(60 \mu \mathrm{mol})$ or $1.80 \mathrm{mg}\left[\mathrm{U}_{-}{ }^{13} \mathrm{C}, \mathrm{D}\right]$ glucose $(10 \mu \mathrm{mol}) .150 \mu \mathrm{L}$ sample was transferred to a sample cup.

Cancer cell growth. Human prostate adenocarcinoma cells (PC3) and human mammary adenocarcinoma cells (MCF7) were grown to approximately $90 \%$. Cells were grown in flasks $\left(175 \mathrm{~cm}^{2}\right)$ in an environment with $5 \% \mathrm{CO}_{2}$, at $37{ }^{\circ} \mathrm{C}$ in RPMI-1640 medium with FBS and antibiotics. Cells were harvested by trypsination, washed and resuspended in $40 \mathrm{mM}$ phosphate buffer $\mathrm{pH} 7.3$ to a concentration of 20 million cells $/ \mathrm{mL}$.

Metabolite samples, cell extracts. $500 \mu \mathrm{L}$ cell suspension (10 mio. cells) in $2 \mathrm{~mL}$ Eppendorf tubes were placed in a shaking thermostat at $37{ }^{\circ} \mathrm{C} .100 \mu \mathrm{L}\left[\mathrm{U}-{ }^{13} \mathrm{C}, \mathrm{D}\right]$ glucose $(120 \mathrm{mM})$ were added and the cells were incubated for 0,1 , 3,10 or $30 \mathrm{~min}$, respectively. Following incubation, the entire cell suspension was quenched with perchloric acid (PCA): $400 \mu \mathrm{L}$ ice cold $2.2 \mathrm{M}$ PCA solution was added to $600 \mu \mathrm{L}$ cell suspension and placed on ice for at least 10 min. Soluble metabolites were extracted by centrifugation (10 min, 10,000 rpm, $4^{\circ} \mathrm{C}$ ). Supernatant was $\mathrm{pH}$ neutralized with $\mathrm{KOH}$, centrifuged and freeze-dried. The lyophilized samples were dissolved with $150 \mu \mathrm{L}$ polarization medium (70 mg OX063, $1227 \mathrm{mg}$ glycerol, $944 \mathrm{mg}$ Milli-Q-water and $28.8 \mathrm{mg}$ Gadoteridol $(100 \mu \mathrm{mol} / \mathrm{g})$ and $5 \mu \mathrm{L} \mathrm{HP} 001$ $(50 \mathrm{mM})$ was added as an internal standard.

Metabolite samples, unlabeled. Signal loss coefficient (SLC) measured using unlabeled metabolites consisted of $75 \mu \mathrm{mol}$ of each compound (3-phosphoglycerate (3PG), dihydroxyacetone phosphate (DHAP) or phosphoenolpyruvate (PEP)) mixed with $300 \mu \mathrm{L}$ polarization medium as described under cell extracts, $15 \mu \mathrm{L}$ HP001 $(50 \mathrm{mM})$ and $5.4 \mathrm{mg}\left[\mathrm{U}-{ }^{13} \mathrm{C}, \mathrm{D}\right]$ glucose. Difference in $\mathrm{pH}$ dependency of the chemical shift for $3 \mathrm{PG}$ and $6 \mathrm{PG}^{7}$ was used to identify $3 \mathrm{PG}$ as the observed metabolite (Figure S3).

Dynamic nuclear polarization. $q d \mathrm{DNP}$ was performed at $3.35 \mathrm{~T}$ and $1.4 \mathrm{~K}$ in a HyperSense polarizer with microwave irradiation at $f_{\mu w}=94 \mathrm{GHz}$ and $P_{\mu w}=100 \mathrm{~mW}$. Technical samples were polarized for 30,90 or $240 \mathrm{~min}$, respectively. Metabolite samples were polarized for 90 min. All samples were dissolved with $5 \mathrm{~mL}$ phosphate buffer ( $40 \mathrm{mM}, \mathrm{pH} 7.4)$ and transferred to a $9.4 \mathrm{~T}$ NMR spectrometer into a $5 \mathrm{~mm}$ NMR tube in approx. $12 \mathrm{~s}$.

NMR Spectroscopy, $q d$ DNP. All samples were measured in a 9.4 T Varian spectrometer at $37{ }^{\circ} \mathrm{C} .{ }^{13} \mathrm{C}$ 1D NMR spectra of metabolite samples were acquired with a $70^{\circ}$ pulse. ${ }^{13} \mathrm{C}-1 \mathrm{D}-\mathrm{NMR}$ spectra of technical samples were obtained with a series of $5^{\circ}$ pulses acquired every $3 \mathrm{~s}$.

NMR Spectroscopy, Thermal NMR. $75 \mu \mathrm{L}$ DNP sample was dissolved in $400 \mu \mathrm{L}$ phosphate buffer $(40 \mathrm{mM}, \mathrm{pH}$ 7.3), $75 \mu \mathrm{L} \mathrm{D}{ }_{2} \mathrm{O}$ and $15 \mu \mathrm{L}$ Omniscan. ${ }^{13} \mathrm{C}$ 1D NMR spectra were recorded on a Bruker $800 \mathrm{MHz}$ spectrometer with cryoprobe using a delay of $2 \mathrm{~s}$ and 4096 scans.
Data Processing. NMR spectra were processed with MNova. Statistical analysis was done with Python using SciPy. ${ }^{8,9}$

\section{RESULTS AND DISCUSSION}

\section{Optimization of DNP sample preparation.}

Quantification of biological extracts requires a general and robust polarization matrix compatible with an ensemble of different metabolites. A mixture of $50 \%$ water $/ 50 \%$ glycerol was used with the trityl radical OX063 and a gadolinium-DOTA complex as described in general principles by Karlsson et al. ${ }^{10}$ HP001 was chosen as internal reference compound due to its favorable properties such as spectral position, long $T_{1}$ on the quaternary carbon, high solubility and chemical stability. ${ }^{4}$ To simulate the conditions in a metabolite sample, $\left[\mathrm{U}-{ }^{13} \mathrm{C}, \mathrm{D}\right]$ glucose was added along with the standard compound to the polarization matrix.

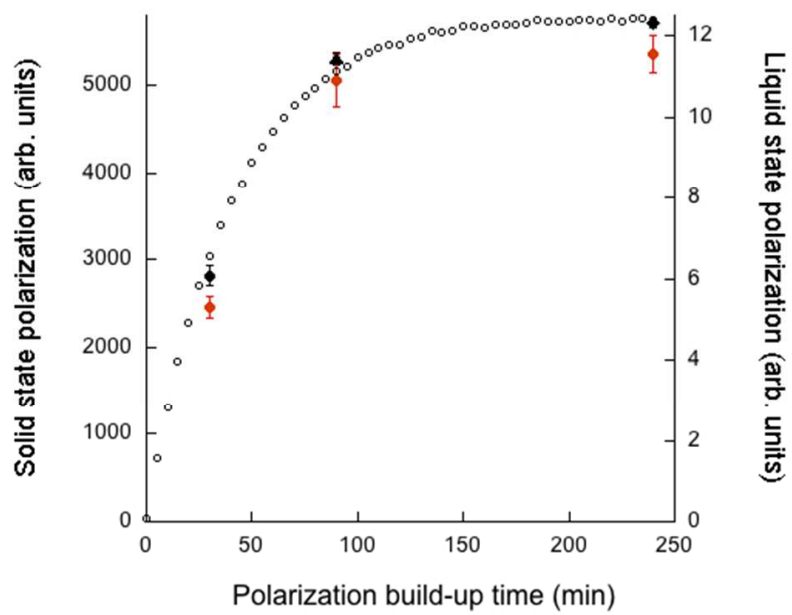

Figure 1. Solid-state polarization build-up of ${ }^{13} \mathrm{C}$ signal in the general polarization matrix consisting of $50 \%$ water, 50\% glycerol, OX063 radical and Gd-complex (black symbols, $n=3$ ). The corresponding liquid state polarization of the standard compound HP001 (red symbols) is shown as comparison $(n=3$ for 30 and 90 $\min$ and $n=2$ for 240 min polarization time).

The samples were polarized for 30,90 and $240 \mathrm{~min}$ to find the best time point for dissolution (Figure 1). For each time point the solid-state polarization is repeatable (a.u. $2817 \pm$ $114,5311 \pm 74$ and $5716 \pm 57$ for respectively 30,90 and $240 \mathrm{~min}$ ). After $90 \mathrm{~min} 93 \%$ of the maximal achievable polarization is reached. This time point was therefore chosen for samples where optimal SNR is important. It is evident that reducing the polarization time to $30 \mathrm{~min}$ can increase the throughput of the method. In this case ca. $50 \%$ of the maximal polarization can be achieved. After dissolution, the integral of the standard compound (HP001) follows the solid-state build-up as expected (Figure 1, red symbols). The polarization matrix used here is optimized 
with respect to radical, Gd-complex and ${ }^{13} \mathrm{C}$ concentration. A relatively broad maximum around $15 \mathrm{mM} \mathrm{OX063} \mathrm{has}$ been found in the literature for polarization matrices. ${ }^{10} \mathrm{Ad}-$ dition of gadolinium increases the polarization at $3.35 \mathrm{~T}$ with $60 \%$ (Table S2). Ludwig et al. ${ }^{11}$ have suggested that ${ }^{13} \mathrm{C}$ labeled additives can increase the polarization by increasing the spin diffusion. In accordance with this we observe a $50 \%$ decrease of the polarization if the $\left[\mathrm{U}-{ }^{13} \mathrm{C}, \mathrm{D}\right]$ glucose is replaced by natural abundance glucose (Table S2). To obtain maximum signal in the solid state $60 \mu \mathrm{mol}$ of $\left[\mathrm{U}-{ }^{13} \mathrm{C}, \mathrm{D}\right]$ glucose was applied but even at $10 \mu \mathrm{mol}[\mathrm{U}-$ ${ }^{13} \mathrm{C}$,D] glucose $83 \%$ of the maximum polarization can be achieved (Table S2). At optimum conditions a liquid state polarization of $20 \%$ on glucose C1 was obtained after 240 min polarization followed by dissolution and $12 \mathrm{~s}$ manual transfer time. This corresponds approximately to a solidstate polarization of $44 \%\left(\mathrm{~T}_{1}=15 \mathrm{~s}, 9.4 \mathrm{~T}\right)$.

Quantification of metabolites. The liquid state polarization level was measured for four often-occurring metabolites (lactate, acetate, alanine and pyruvate) polarized at three different time points (30,90 and $240 \mathrm{~min})$. The absolute integrals are reproducible for a given polarization time (Figure 2) but over longer time periods the stability of the polarizer can influence these. ${ }^{12}$ For the method to be robust the quantification of the metabolites is thus based on the ratio to an internal standard (HP001). This ratio is stable and independent of the polarization time for each metabolite with a coefficient of variation of $4.5 \%\left({ }^{13} \mathrm{C}_{1}\right.$-lactate $)$, $7.4 \%\left({ }^{13} \mathrm{C}_{1}\right.$-acetate $), 6.1 \%\left({ }^{13} \mathrm{C}_{1}\right.$-alanine $)$ and $15.7 \%\left({ }^{13} \mathrm{C}_{1}\right.$ pyruvate), $n=9$. Transport of the sample from the polarizer to the NMR spectrometer represents in many cases an uncontrolled magnetic environment. For our current setup with a $12 \mathrm{~s}$ transfer time the method is limited to quaternary and deuterated carbon positions. Other laboratories have minimized losses of polarization in the sample transfer step by implementation of magnetic and temperature controlled transfer lines. ${ }^{13,14}$ Although these solutions are important for optimization of assay sensitivity and reproducibility, robust quantification of metabolites demands that individual signal decay is taken into account. ${ }^{12}$ To account for signal decay during transfer for all identified metabolites, a signal loss coefficient (SLC) was determined relative to the internal standard and compared to the ratio obtained with conventional thermal ${ }^{13} \mathrm{C}$ NMR. (Table 1). For the tested compounds the SLC varies from 55-108\%. Alanine has the lowest SLC. This could be expected based on a short $\mathrm{T}_{1}$ at 9.4 T (22 s, Table S3) and the observation that amino acids are sensitive to the dissolution process. ${ }^{15}$ The line width of the four molecules in Figure 2A $(2.9 \mathrm{~Hz}$ vs. $10.1 \mathrm{~Hz}$ for pyruvate and alanine, respectively) reveals that pyruvate has a longer $T_{2}$ than the other three molecules. Due to these metabolite specific relaxation behaviors the SLC must be determined for each metabolite to be able to calculate absolute concentrations.
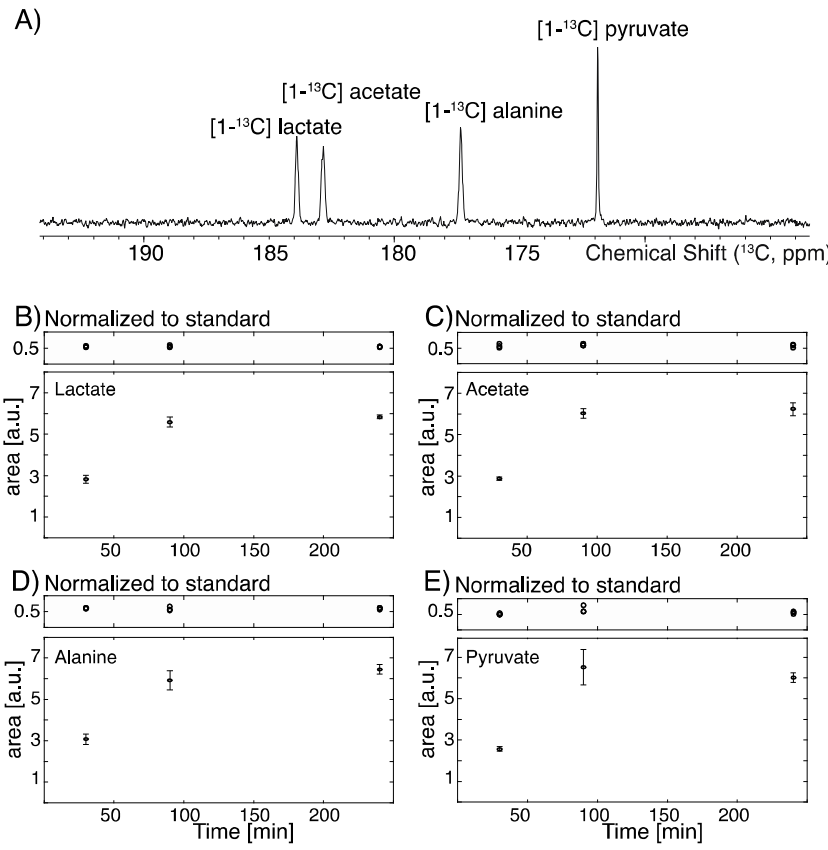

Figure 2. A) Example of spectrum after dissolution of four metabolites after 90 min polarization. B-E) Measured integrals of the dissolved samples after 30-240 min. polarization. Top panels show ratio to internal standard (HP001).

Table. 1. Signal loss coefficient (SLC). Metabolite ratios relative to the standard HP001 from the DNP experiment is calibrated to the values obtained with thermal NMR $(\mathrm{SLC}=\mathrm{DNP}$ ratio/NMR ratio).

\begin{tabular}{|c|c|c|c|}
\hline $\begin{array}{c}\text { Compound } \\
\text { (Com) }\end{array}$ & $\begin{array}{c}\text { DNP ratio } \\
\text { (Com/HP001) }\end{array}$ & $\begin{array}{c}\text { NMR ratio } \\
\text { (Com/HP001) }\end{array}$ & SLC \\
\hline Lactate, $\mathrm{C} 1$ & $0.55 \pm 0.03$ & $0.67 \pm 0.07$ & $82 \pm 8 \%$ \\
\hline Acetate, $\mathrm{C} 1$ & $0.58 \pm 0.04$ & $0.61 \pm 0.04$ & $95 \pm 6 \%$ \\
\hline Alanine, $\mathrm{C} 1$ & $0.60 \pm 0.04$ & $1.08 \pm 0.01$ & $55 \pm 4 \%$ \\
\hline Pyruvate, $\mathrm{C} 1$ & $0.57 \pm 0.09$ & $0.53 \pm 0.01$ & $108 \pm 9 \%$ \\
\hline
\end{tabular}

Identification and quantification of characteristic metabolites in cancer cells. Breast cancer cells (MCF7) and prostate cancer cells (PC3) were incubated with [U- $\left.{ }^{13} \mathrm{C}, \mathrm{D}\right]$ glucose for $1,3,10$ and $30 \mathrm{~min}(\mathrm{n}=3)$. The entire cell suspensions were arrested and soluble metabolites were extracted and analyzed as discussed above. A distinct cell type dependent metabolic pattern is showing itself already at $10 \mathrm{~min}$ incubation time but is highly evident after $30 \mathrm{~min}$ incubation with $\left[\mathrm{U}_{-}{ }^{13} \mathrm{C}, \mathrm{D}\right]$ glucose, Figure 3. For comparison a thermal NMR spectrum acquired on a $600 \mathrm{MHz}$ spectrometer over night on an identical sample only reveals lactate (MCF7, 30 min, Figure S1). 
A)

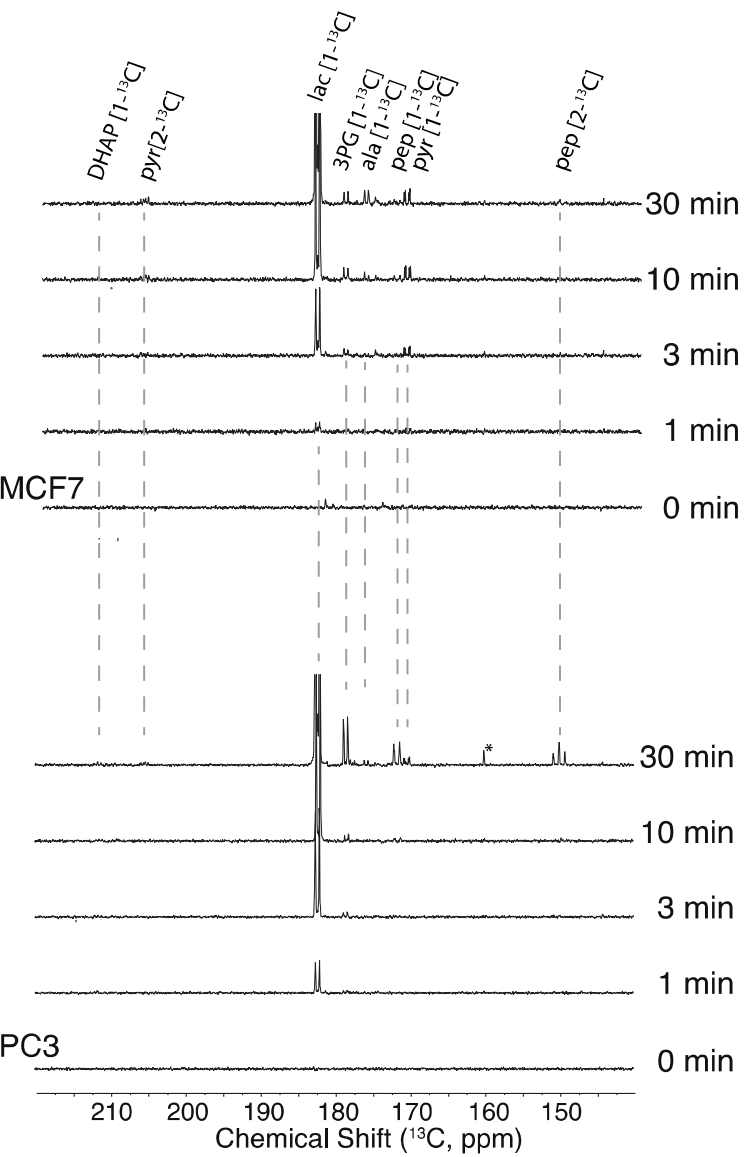

C)
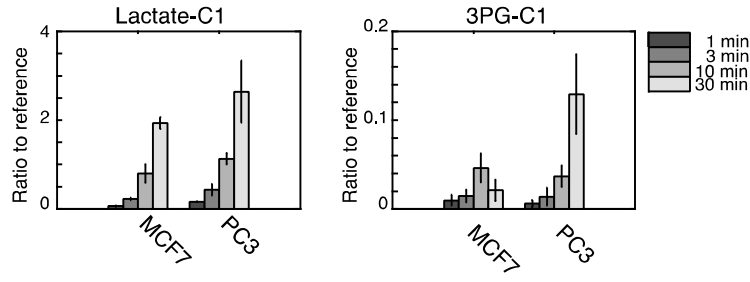

Figure 3 A-B) Example of dDNP-NMR spectra of metabolite extracts from two cancer cell lines (MCF7, breast cancer and $\mathrm{PC} 3$, prostate cancer). The cells have been incubated with $\left[\mathrm{U}-{ }^{13} \mathrm{C}, \mathrm{D}\right]$ glucose for time points $0,1,3,10$ and $30 \mathrm{~min}$. Chemical shifts are referenced to HP001 at $23.7 \mathrm{ppm}$ and metabolite assignments are performed as described in Supporting Information (Table S6). C) Lactate and 3-phosphoglycerate production as function of time relative to an internal standard $(n=3)$.

Both cell types produce large amounts of lactate (about 20 times more than the other observed metabolites), confirming their glycolytic phenotype. While this production is constant over time in MCF7 cells it is decreasing in PC3 cells. Lactate production per minute is halved at $30 \mathrm{~min}$ compared to $1 \mathrm{~min}$ incubation time, $\mathrm{p}<0.01$ (Figure S2). No equivalent change in glucose consumption between the cell types is found based on the remaining glucose signal.
The change in lactate production thus hints to a changed metabolism significant at $30 \mathrm{~min}$ incubation time.

Amounts of identified metabolites can be calculated for the two cell types allowing a direct comparison of fluxes. A signal loss coefficient (SLC) for identified metabolites was obtained with dDNP NMR on unlabeled metabolites polarized under the same conditions as for the metabolite extracts. A list of SLC values for identified metabolites is given in Table 2. Difference in sample preparation such as increased concentration and different labeling schemes do not influence the calculated SLC (Table S4 and S5). Amounts of metabolites identified at $30 \mathrm{~min}$. incubation time in the two cell types were quantified (Figure 4) using the SLC values given in Table 1 and 2.

Table 2. Signal loss coefficients (SLC) for metabolites identified in addition to Table 1.

\begin{tabular}{|c|c|c|c|}
\hline $\begin{array}{c}\text { Com- } \\
\text { pound }\end{array}$ & $\begin{array}{c}\text { DNP ratio } \\
\text { (Com/HP001) }\end{array}$ & $\begin{array}{c}\text { NMR ratio } \\
\text { (Com/HP001) }\end{array}$ & SLC \\
\hline 3PG, C1 & $0.49 \pm 0.01$ & $0.94 \pm 0.02$ & $52 \pm 4 \%$ \\
\hline DHAP, C2 & $0.37 \pm 0.004$ & $0.32 \pm 0.02$ & $116 \pm 1 \%$ \\
\hline pep, C1 & $1.30 \pm 0.01$ & $1.22 \pm 0.09$ & $107 \pm 9 \%$ \\
\hline pep, C2 & $1.42 \pm 0.01$ & $1.18 \pm 0.04$ & $120 \pm 4 \%$ \\
\hline
\end{tabular}

Whereas breast cancer cells produce almost entirely pyruvate (pyr) and its downstream metabolites alanine (ala) and lactate (lac), prostate cancer cells accumulate phosphoenolpyruvate (pep) and dihydroxyacetone phosphate (DHAP). 3-phosphoglycerate (3PG) although produced by both cell types is six times higher in the long incubation times for prostate cancer cells as shown in Figure 3C. This high increase in $3 \mathrm{PG}$ follows the relative decrease in lactate production in $\mathrm{PC} 3$ cells at long incubation times and may reflect alternative use of glucose metabolism such as e.g. build-up of amino acids. This interpretation is supported by the both upstream and downstream accumulation of glycolytic intermediates.

\section{CONCLUSIONS}

By inverting the steps involved in a real-time cellular dDNP experiment, and incubating living cells with an isotope enriched substrate before subjecting the metabolite(s) to hyperpolarization, we prolong the time window from a few minutes to hours. The time frame will be dependent on the biological model rather than on the $\mathrm{T}_{1}$ of the tracer. We show in this work that NMR analysis of hyperpolarized metabolite extracts following substrate incubation can be quantitative provided that an internal standard is applied in combination with laboratory dependent calibrations. The former is straightforwardly added to the analyte and the latter is determined as one-time corrections unique for each metabolite. 
1

2

3

4

5

6

7

8

9

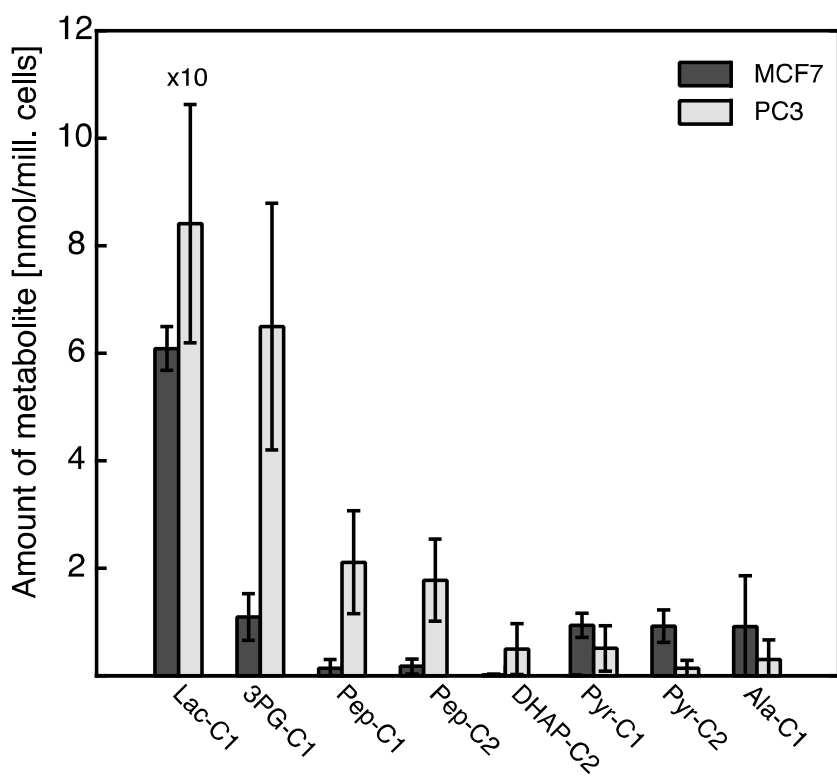

Figure 4. Quantitative metabolic fingerprint from 30 min incubation of MCF7 and PC3 cell line with [U${ }^{13} \mathrm{C}, \mathrm{D}$ ] glucose $(\mathrm{n}=3)$.

In combination, the extended time scale and quantitative signal enhancement of extracts allow metabolite driven hypotheses in cellular biochemistry. In the example discussed here the metabolic pattern of MCF7 cells support a highly glycolytic phenotype with accumulated downstream metabolites of pyruvate, lactate and alanine. The metabolic pattern of PC3 cells is more complex: Both DHAP and pep accumulate supporting that the active isoform of pyruvate kinase (PKM2) in cancer is inhibited in aggressive prostate cancer cells. ${ }^{16}$ The accumulation of $3 \mathrm{PG}$ suggests alternative use of energy production such as activation of the serine/glycine pathway resulting in an apparent decrease in lactate formation at long incubation times.

The presented work describes a method by which, in cell metabolite analysis can be performed with high sensitivity and high accuracy and precision. Such a method is a means to bring biological insight from a new level of measurable metabolites.

\section{ASSOCIATED CONTENT}

\section{Supporting Information}

Additional tables and figures in support of sample preparation, SLC, lactate production and assignment of metabolites especially 6 PG versus 3 PG $(\mathrm{PDF})$.

\section{AUTHOR INFORMATION}

Corresponding Author

\#E-mail: peroje@elektro.dtu.dk

Author contribution
All authors have given approval of the final version of the manuscript. *These authors contributed equally.

Notes

The authors declare no competing financial interest.

\section{ACKNOWLEDGEMENTS}

The authors gratefully acknowledge funding by the Danish National Research Foundation (grant DNRF124) and Sebastian Meier for NMR data acquisition at the NMR Center•DTU.

\section{REFERENCES}

(1) Fan, T.W.; Lane, A.N. Prog Nucl Magn Reson Spectrosc. 2016, 92-93, 18-53.

(2) Ardenkjaer-Larsen, J.H.; Fridlund, B.; Gram, A.; Hansson, G.; Hansson, L.; Lerche, M.H.; Servin, R.; Thaning, M.; Golman, K. Proc Natl Acad Sci U S A. 2003, 100(18), 10158-63.

(3) Lerche, M.H.; Jensen, P.R.; Karlsson, M.; Meier, S. Anal Chem. 2015, 87(1), 119-32.

(4) Lerche, M.H.; Meier, S.; Jensen, P.R.; Hustvedt, S. O.; Karlsson, M.; Duus, J.O.; Ardenkjaer-Larsen, J.H. NMR Biomed 2011, 24(1), 96-103.

(5) Christensen C.E.; Karlsson M.; Winther J.R.; Jensen P.R.; Lerche M.H. J Biol Chem. 2014, 289(4), 2344-52.

(6) Dumez, J. N.; Milani, J.; Vuichoud, B.; Bornet, A.; LalandeMartin, J.; Tea, I.; Yon, M.; Maucourt, M.; Deborde, C.; Moing, A Et al. Analyst. 2015, 140(17), 5860-3.

(7) Jensen, P.R. and Meier, S. Chem. Comm. 2016, 52; 2288-2291.

(8) Python Software Foundation. Python Language Reference, version 3.5. Available at http://www.python.org.

(9) Jones, E.; Oliphant, E.; Peterson, P. SciPy: Open Source Scientific Tools for Python, http://www.scipy.org/ (date 2017-Sep17).

(10) Karlsson, M.; Jensen, P.R.; Duus, J. O.; Meier, S.; Lerche, M.H. Appl Magn Res, 43(1-2), 223-236.

(11)Ludwig C1, Marin-Montesinos I, Saunders MG, Günther UL J Am Chem Soc. 2010; 132(8), 2508-9.

(12) Bornet, A.; Maucourt, M.; Deborde, C.; Jacob, D.; Milani, J.; Vuichoud, B.; Ji, X.; Dumez, J.N.; Moing, A.; Bodenhausen, G.; Jannin, S.; Giraudeau, P. Anal Chem. 2016, 88(12), 6179-83.

(13) Bowen, S.; Hilty, C. Phys Chem Chem Phys. 2010, 12(22), 5766-70.

(14) Milani, J.; Vuichoud, B.; Bornet, A.; Miéville, P.; Mottier, R.; Jannin, S.; Bodenhausen, G. Rev Sci Instrum. 2015 ， 86(2), 024101 .

(15) Jensen, P. R.; Karlsson, M.; Meier, S.; Duus, J.O.; Lerche, M.H. Chemistry 2009, 15, 10010-2.

(16) Vander Heiden, M.G.; Lunt, S.Y.; Dayton, T.L.; Fiske, B.P.; Israelsen, W.J.; Mattaini, K.R.; Vokes, N.I.; Stephanopoulos, G.; Cantley, L.C.; Metallo, C.M.; Locasale, J.W. Cold Spring Harb Symp Quant Biol. 2011, 76, 325-34. 
For TOC only

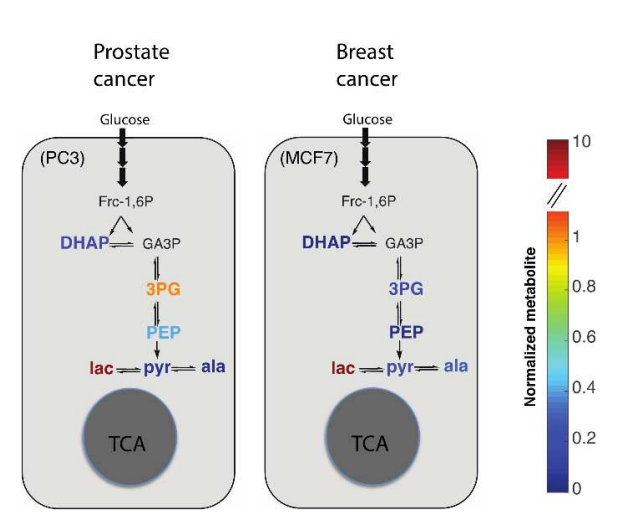

